Special Issue of the 8th International Advances in Applied Physics and Materials Science Congress (APMAS 2018)

\title{
The Effect on Mechanical Properties of Pressing Technique in PM Steels
}

\author{
M.A. ERDEN ${ }^{a, *}$ AND B. AYVACI ${ }^{b}$ \\ ${ }^{a}$ Karabük University, Faculty of Engineering, Department of Mechanical Engineering, 78050, Karabuk, Turkey \\ ${ }^{b}$ Karabük University, Institute of Science and Technology, Department of Manufacturing Engineering, \\ 78050, Karabuk, Turkey
}

\begin{abstract}
In this work, the effect of pressing technique on the microstructures and tensile behaviors of powder metallurgy (PM) steel with different composition were investigated. Weighed powders for the desired chemical composition were mixed in an industrial conic mixer for $1 \mathrm{~h}$ and then cold and warm pressed at $700 \mathrm{MPa}$ with a die. The pressed PM steels were sintered at $1400^{\circ} \mathrm{C}$. PM steels with different pressing technique were analyzed in terms of micrstructure and tensile test. Results indicated that PM steels with warm pressing technique showed the highest values in yield strength (YS) and ultimate tensile strength (UTS).
\end{abstract}

DOI: 10.12693/APhysPolA.135.1078

PACS/topics: powder metallurgy, steels, microstructure, mechanical properties, pressing technique

\section{Introduction}

The steels are manufactured in different specifications according to the purpose of use of the industry. AISI 4140 steel is a commercial medium carbon low alloy steel and widely used in manufacturing of tools, gears and bolts. The mechanical properties of the steels vary considerably depending on the alloying elements in the chemical composition, their construction, the grain sizes and the heat treatments applied [1]. Alloying elements in products affect mechanical properties [2]. The main alloying elements of tool steels are carbon and carbide forming elements like $\mathrm{Cr}$, Mo and $\mathrm{Al}$ [3]. Molybdenum prevents the grain growth and increases the strength of steels when it presents in solid solution or as precipitate particles. Junhua et al. [3] investigated the effect the Mo content on the microstructure and mechanical properties of pipeline steel. It was concluded that, the amount of Mo content increased, which resulted in an increment in yield and tensile strength. While chromium is a strong carbide former element, it is cheap, common and, it increases corrosion resistance, especially to intercrystalline corrosion. It increases hardenability and improves high temperature strength [4]. PM varies greatly between metal processing technologies is a production technique [5]. Certain studies on microstructure or mechanical properties of PM steels are available in the literature. For instance, Erden studied the $\mathrm{Nb}-\mathrm{V}$ microalloyed steel with the PM method. The sintering process was carried out at 1150 , 1250,1350 and $1400^{\circ} \mathrm{C}$. Yhe results confirmed that yield strength and tensile strength increase as $\mathrm{Nb}$ and $\mathrm{V}$ ratios $(0.1 \%-0.2 \%)$ increase. The mechanism was the formation of precipitates like $\mathrm{NbC}(\mathrm{N})$ and $\mathrm{VC}(\mathrm{N})$ during the sintering and post-sintering cooling period [5].

*corresponding author; e-mail: makiferden@karabuk.edu.tr
In the present study, AISI 4140 PM steel has been transformed into the targeted compound by adding different proportions of alloy elements into Fe matrix with the powder metallurgy method. The mechanical properties have been compared with cold and warm pressed AISI 4140 PM steel specimens prepared with the same method.

\section{Experimental procedure}

In this study, the AISI 4140 PM steel samples (0.4 wt\%C, 1 wt\% Cr, 0.25 wt $\%$ Mo, 0.075 wt $\% \mathrm{Ni}$, 0.075 wt $\% \mathrm{Al}, 0.25 \mathrm{wt} \% \mathrm{Cu}$, rest $\mathrm{Fe}$ ) were produced in the desired compositions with the PM method. Before the mixing process, the powders were prepared by weighing on a digital precision scale of $0.0001 \mathrm{~g}$ precision. The mixing process was conducted without ball using a Turbula T2F mixer for 1 hour. Having mixed homogeneously, the powders were pressed with cold and warm at $150{ }^{\circ} \mathrm{C}$ under $700 \mathrm{MPa}$ unidirectionally with a Hidroliksan press of 96 ton pressure capacity according to ASTM (E8M) standards of powder metal material tension test sample. The pressed samples were sintered at $1400^{\circ} \mathrm{C}$ for $1 \mathrm{~h}$ in argon atmosphere. Tensile test was made at $0.5 \mathrm{~mm} / \mathrm{min}$ crosshead speed with Shimadzu tensile device that has $50 \mathrm{KN}$ capacity. The tensile strength and elongation of the tensile test samples were determined. After sintering, density were measured. Microstructure examinations were carried out with Nikon Epiphot 200 brand optical microscope. Density of the samples was measured with the density measurement tool according to Archimedes principle.

\section{Results and discussion}

Figure 1 shows the stress-strain diagrams of the sintered samples. In Fig. 2 the mechanical properties of Alloy 2 and Alloy 3 are compared. $\mathrm{C}, \mathrm{Ni}, \mathrm{Al}$ and $\mathrm{Cu}$ ratios 


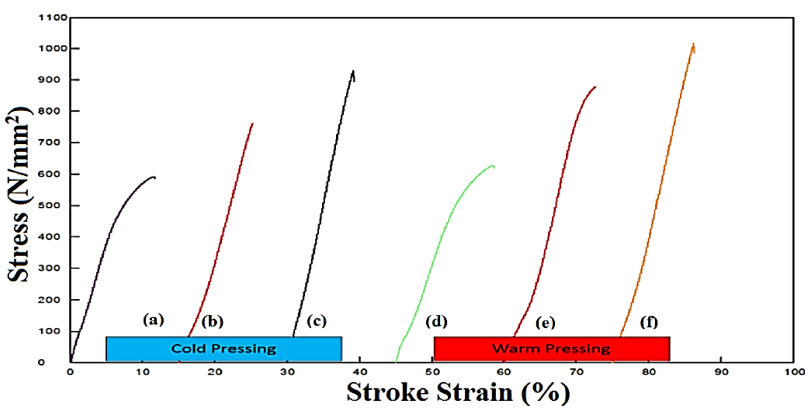

Fig. 1. The stress-strain curves for the PM AISI 4140 steel at different percentages of $\mathrm{Cr}$ and Mo content: (a) Alloy 1 with cold pressing, (b) Alloy 2 with cold pressing, (c) Alloy 3 with cold pressing, (d) Alloy 1 with warm pressing, (e) Alloy 2 with warm pressing and (f) Alloy 3 with warm pressing.
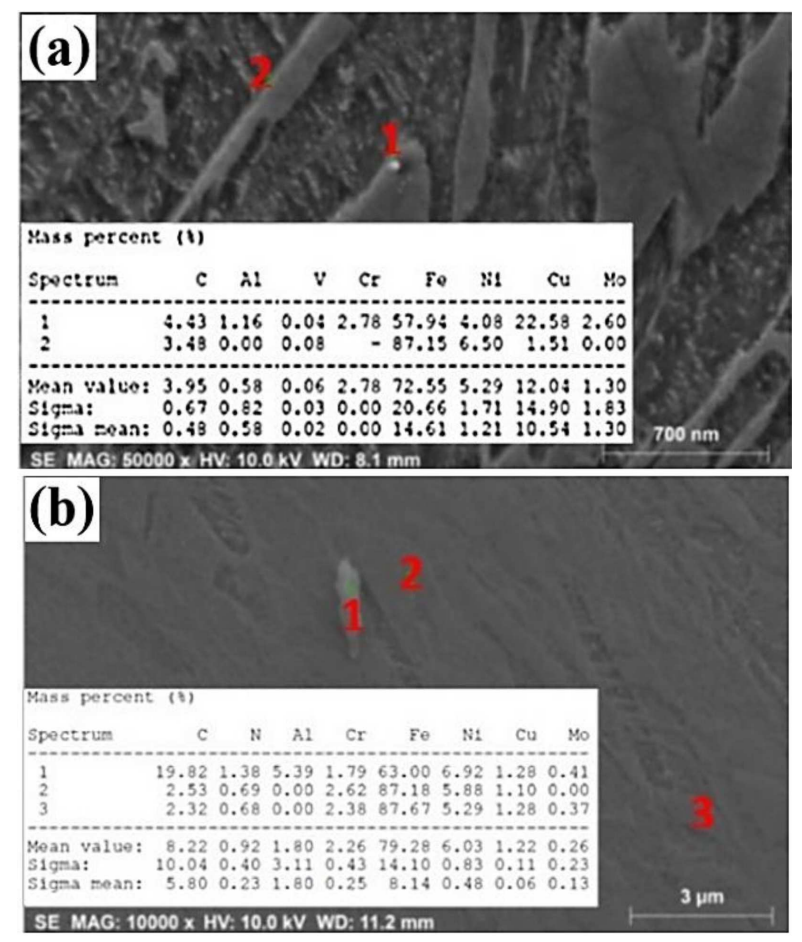

Fig. 2. SEM images of (a) Alloy 2 and (b) Alloy 3 with corresponding EDS of the indicated points.

are kept constant and the effect of $\mathrm{Cr}$ and Mo contents is examined. The mechanical properties of Alloy 3 is better than that of Alloy 1. For example after warm pressing ultrahigh tensile strength (UTS) and elongation of Alloy 1 is $620 \mathrm{MPa}$ and $14 \%$, vs. $1019 \mathrm{MPa}$ and $12 \%$ for Alloy 3 . In addition, the mechanical properties of warm pressed samples are better than that of cold pressed samples and the warm pressing of the samples increased the density of the samples. For example, while density of Alloy 1 after cold pressing is $7.3418 \mathrm{~g} / \mathrm{cm}^{3}$, that with warm pressing is $7.3876 \mathrm{~g} / \mathrm{cm}^{3}$. It affects mechanical properties positively (see Fig. 1). Cr and Mo elements form precipitates during the sintering process. It improves the tensile strength due to the mechanisms like precipitation hardening and grain size refinement. Anther studies also support these results [6]. The values of UTS increase remarkably after warm pressing due to grain refinement and predominantly attributed to the grain boundary strengthening, formation of microstructure and decrease porosity.

The EDS measurements show that $\mathrm{Cr}$, Mo and Al elements exist in the solution as precipitates (Fig. 2). SEM micrographs of various Cr-Mo compounds in Fig. 3 (next page) reveal precipitates of different sizes. Erden [5] had investigated the precipitates behavior in low carbon microalloyed steel containing $\mathrm{V}$ and $\mathrm{Nb}$. The results showed that both $\mathrm{VC}(\mathrm{N})$ and $\mathrm{NbC}(\mathrm{N})$ precipitate in the austenite, forming $\mathrm{VNbC}(\mathrm{N})$ precipitates when $\mathrm{Nb}-\mathrm{V}$ is added to the steel. The EDS point analysis of the precipitate detected $\mathrm{Cr}, \mathrm{Mo}$ and $\mathrm{Al}$ and the amount of $\mathrm{C}$ and $\mathrm{N}$ was clearly higher in comparision with the EDS point analysis taken from the matrix (see Fig. 2). Comparision of the EDS point analysis results at this study to that of older works [6] suggests, that the precipitate is $\mathrm{Cr}, \mathrm{MoC}(\mathrm{N})$ and $\operatorname{AlC}(\mathrm{N})$.

The microstructure of the samples is shown in Fig. 3. $\mathrm{Cr}$ and Mo elements promote the formation of hard phases such as pearlite, bainite and martensite. As can be seen, the microstructure of Alloy 1 (AISI 4140) is mainly ferritic-pearlitic, Alloy 2 (AISI 4140-3Cr) samples are mainly pearlitic-bainitic in structure, whereas Alloy 3 (AISI 4140-3Cr-3Mo) samples are mainly martensiticbainitic.

\section{Conclusion}

Results indicate, that Alloy 3 (PM AISI 4140 steels with $3 \mathrm{wt} \% \mathrm{Cr}-3 \mathrm{wt} \% \mathrm{Mo}$ ) show the highest values of yield strength (YS) and ultimate tensile strength (UTS). PM steels obtained with warm pressing technique show ultimate mechanical properties.

\section{Acknowledgments}

This work was supported by Scientific Research Projects Coordination Unit of Karabük University (Karabük, Turkey). Project Number: KBÜ-BAP18YL-017.

\section{References}

[1] L. Lv, L. Fu, S. Ahmad, A. Shan, Mater. Sci. Engin A 704, 469 (2017).

[2] F. Omaç, D. Ozyurek, M. Erer, Acta Phys. Pol A 131, 165 (2017).

[3] K. Junhua, Z. Lin, G. Bin, L Pinghe, W Aihua, X Changsheng, Mater. Des. 25, 723 (2004).

[4] W. Li, L. Xu, L. Qiao, J Li, Appl. Surf. Sci. 42, 32 (2017).

[5] M.A. Erden, Metals 7, 329 (2017).

[6] A. Fadel, D. Glisic, N Radovicy, D Drobnjak, J Mater. Sci. Technol. 28, 1053 (2012). 


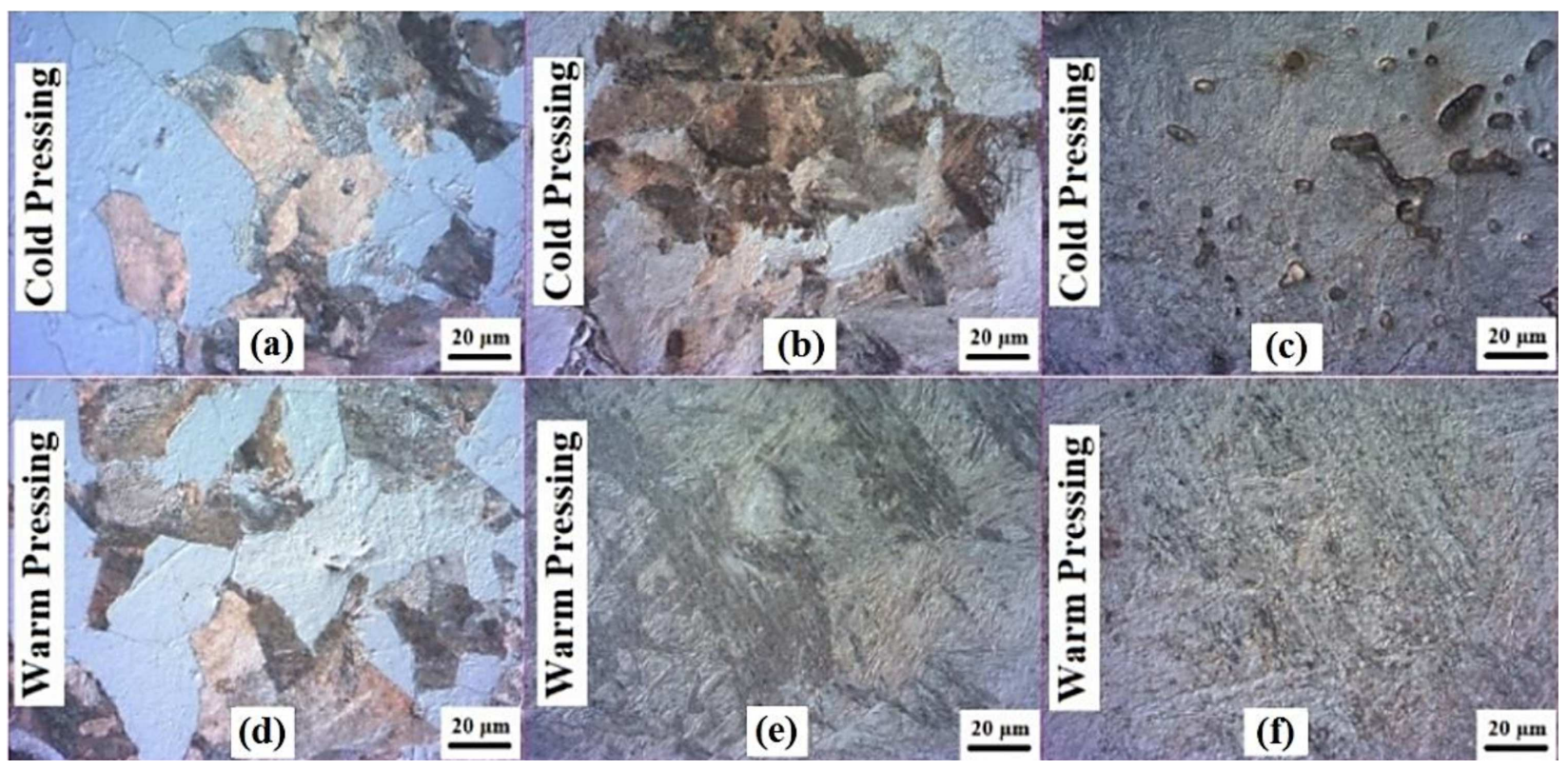

Fig. 3. Micrographs of the PM AISI 4140 steel at different percentages of Cr and Mo content: (a) Alloy 1 with cold pressing, (b) Alloy 2 with cold pressing, (c) Alloy 3 with cold pressing, (d) Alloy 1 with warm pressing, (e) Alloy 2 with warm pressing and (f) Alloy 3 with warm pressing. 